\title{
Bariatric Procedures Unmasking Celiac Disease
}

\begin{abstract}
Keywords: Celiac disease; Bariatric surgery
Abstract

Celiac disease is being recognized more frequently but often rema ins undiagnosed. Celiac disease patients a re inc reasingly obese. Major operation in patients with celiac disease may cause symptoms which lead to the diagnosis, termed "unmasking." We report three patients undergoing bariatric procedures which led to unmasking

Three patients undergoing bariatric procedures for morbid obesity were subsequently diagnosed with celiac disease. A 42-year old female underwent gastric bypass. Her body mass index was 77 preoperatively and open gastric bypass with a $150 \mathrm{~cm}$ Roux Limb was performed. At 18 months her body mass index was 51 and she had no dianhea. A malabsorptive revision moved the Roux Limb connection to $60 \mathrm{~cm}$ proximal to the cecum. One yearlater she had a body mass index of 36 and diamhea. Persistent diamhea and weight loss in the following two years led to serologic diagnosis of celiac disease. On a gluten-free diether diamea improved and her weight increased $6 \mathrm{~kg}$. A 30-year-old female underwent gastric band. Her body mass index was 46 preoperatively. After multiple adjustments a band slip repair was perfomed at two years and the band was removed at four years. Body mass index was 42 at that time. Within a few months she developed early satiety, abdominal pain and distension, and hepatomegaly. Serology and histology diagnosed celiac disease and a gluten-free diet was instituted. A 36-year-old female underwent biliopancreatic diversion. Her body mass index was 48 preoperatively and decreased to 22 in two years. Persistent diamea led to serologic evaluation for celiac disease. She was started on a gluten-free diet and her body mass index increased to 27 at five years and 30 at ten years postoperatively.
\end{abstract}

Celiac disease should be suspected and evaluated in patients who develop suggestive symptoms after bariatric procedures, including those associated with malabsorption.

\section{Abbreviations}

CD: Celiac Disease; GFD: Gluten-Free Diet; GBP: Gastric Bypass; BMI: Body Mass Index; PBD: Pancreatico Biliary Diversion; DH: dermatitis herpetiformis

\section{Introduction}

Celiac disease $(\mathrm{CD})$ is a disorder characterized by intestinal inflammation and villus atrophy induced by ingestion of rye, wheat and barley in genetically susceptible individuals. The prevalence of $\mathrm{CD}$ is approximately $0.7 \%$ [1]. The classic clinical presentation of CD is chronic diarrhea, malabsorption and weight loss; however, up to $13 \%$ of patients are overweight $[2,3]$. Furthermore, a gluten-free diet (GFD) helps patients regain lost weight and may also cause patients to become overweight [3-5].

$\mathrm{CD}$ is often silent and undiagnosed. Patients with undiagnosed CD may become symptomatic following operation. Subsequent evaluation then leads to the diagnosis, termed "unmasking" [6]. Initial reports of this phenomenon occurred following upper gastrointestinal procedures such as fundoplication and gastrectomy [6]; however, unmasking has been subsequently described following a variety of intraabdominal and extraabdominal procedures [7-14].

\section{Journal of Obesity and Bariatrics}

Jane M. Tsui, Jon S. Thompson*, Vishal M. Kothari and Corrigan L. Mc Bride

Department of Surgery University of Nebraska Medical Center, USA

\section{Address for Correspondence}

Jon S. Thompson, Department of Surgery, 983280 Nebraska Medical Center, Omaha, NE 68198-3280, Phone: 402-559-7182; Fax: 402-5596749; Email: jthompso@unmc.edu

Copyright: (c) 2014 Tsui JM, et al. This is an open access article distributed under the Creative Commons Attribution License, which permits unrestricted use, distribution, and reproduction in any medium, provided the original work is properly cited.

Submission: 20 August 2014

Accepted: 25 August 2014

Published: 30 August 2014

There have been few reports of CD diagnosed in obese individuals after bariatric procedures $[4,7,14]$. We report three further patients undergoing bariatric procedures which led to unmasking of CD.

\section{Methods}

We performed a retrospective review of 512 adult patients $(>19$ years of age) diagnosed with CD over a 22-year period from 1990 to 2012 at our institution [15]. We identified three patients who had the initial diagnosis of $\mathrm{CD}$ made following a bariatric procedure. During this period 1,884 bariatric procedures were performed at our institution.

\section{Results}

A 42-year-old female underwent gastric bypass (GBP). Her body mass index (BMI) was 77 preoperatively and open GBP with a $150 \mathrm{~cm}$ Roux Limb was performed. Intestinal histology was not abnormal. Eighteen months following GBP her BMI was 51 and she had no diarrhea. A malabsorptive revision was performed, moving the Roux Limb connection to $60 \mathrm{~cm}$ proximal to the cecum, shortening the common channel. One year after revision, she had a BMI of 36 and had developed diarrhea. Persistent diarrhea, malabsorption of fat soluble vitamins, and weight loss (BMI 30) two years after revision led to serologic (antigliadin antibody IgA 32EU, $>25$ positive) diagnosis of CD. On a GFD, her diarrhea improved and her weight increased 6 $\mathrm{kg}$ back to a BMI of 32. Repeat intestinal biopsy at that time revealed normal histology.Eight years later she has maintained a BMI of 28.

A 30-year-old female underwent placement of a gastric band. Her BMI was 46 preoperatively. After multiple adjustments a band slip repair was performed two years later. The band was eventually removed at four years after placement. BMI was 42 at that time. Within a few months she developed early satiety, abdominal pain and distension and hepatomegaly. Serology (tissue transglutaminase IgA $74 \mathrm{U} / \mathrm{ml}$ (normal <30) and IgA $343 \mathrm{mg} / \mathrm{dL}$ ) and histology (villous blunting) led to a diagnosis of CD. A GFD was instituted and her symptoms improved. Her BMI was 43 one year later.

A 36-year-old female underwent pancreaticobiliary diversion (BPD) at an outside institution. Her BMI was 48 preoperatively. Her BMI decreased to 22 over the next year. This extreme weight loss combined with her persistent, severe diarrhea led to serologic (negative antigliadin antibody $\operatorname{IgA}(3 \mathrm{U} / \mathrm{ml})$ and $\operatorname{IgG}(0.9 \mathrm{U} / \mathrm{ml})$ 
and tissue transglutaminase $(0 \mathrm{U} / \mathrm{ml})$, but positive IgA endomysial antibody of $226 \mathrm{U} / \mathrm{ml}$ ) evaluation for $\mathrm{CD}$. She was considered at least gluten intolerant and was started on a GFD. Her BMI increased to 27 at five years and 30 at ten years postoperatively.

\section{Discussion}

The increasing prevalence of obesity among patients with $\mathrm{CD}$ has several implications for the bariatric surgeon. Some authors have suggested routine screening of patients for $\mathrm{CD}$ prior to bariatric procedures $[4,16]$. The presence of CD might influence the choice of operation. A GFD might lead to weight gain and negate desired postoperative weight loss. The current report highlights the importance of $\mathrm{CD}$ as a potential cause of malabsorption following bariatric procedures.

The prevalence of CD in morbidly obese individuals appears to be similar to that in the general population. Cuenca-Abente et al [16] performed routine, preoperative endoscopy on 400 bariatric patients and detected $\mathrm{CD}$ in five (1.25\%). Four were clinically silent. All had villous atrophy with serologic confirmation of CD. They recommended routine preoperative endoscopy in patients undergoing evaluation for bariatric surgery. Alternatively, De'Angelis et al. [4] recommend routine serologic screening on bariatric patients with endoscopy performed as indicated. We have not been screening routinely for $\mathrm{CD}$. Two of our three patients identified with $\mathrm{CD}$ postoperatively underwent procedures at our institution during a period when almost 2000 bariatric procedures were performed.

Given the preoperative diagnosis of $\mathrm{CD}$, Cuenca-Abenteet all [16] chose to perform sleeve gastrectomy in these patients rather than GBP. This would avoid malabsorption and maintain an intact gastrointestinal tract for surveillance. GBP and BPD, as performed in two patients in the patient study make diagnosis more challenging.

Weight gain after initiation of a GFD is a potential problem [17]. All three of our patients maintained or regained weight on a GFD. One patient remained morbidly obese.

With the present patient cohort and the three previously reported patients, $\mathrm{CD}$ has now been diagnosed after a full range of bariatric procedures. The initial reports of $\mathrm{CD}$ developing after bariatric procedures were two patients who were diagnosed following jejunoileal bypass. One was diagnosed when severe malabsorption developed nine months later [14]. The other was diagnosed when villous atrophy was identified in an operative specimen [7]. A third report was of a patient diagnosed five years following gastric bypass as part of familial screening [4]. All gained weight on a GFD. All three of our patients became symptomatic postoperatively, which led to evaluation for CD.

Interestingly, two other patients undergoing bariatric procedures have been reported to have developed dermatitis herpetiformis (DH) postoperatively $[18,19] . \mathrm{DH}$ and $\mathrm{CD}$ are both manifestations of gluten-sensitive enteropathy [18]. They are associated with HLA, IgA antitissue and anti-epidermal transglutaminase antibody and blunting of the intestinal villi [20]. DH occurs in 5\% of CD patients, but the majority of $\mathrm{DH}$ patients do not have associated intestinal symptoms [18]. One patient was diagnosed two years after mini-gastric bypass after a one-year history of intermittent itching, excoriation, hyperpigmentation and symmetrically grouped papulovesicles on exterior surfaces. The diagnosis was confirmed by serology and skin biopsy. GFD resolved the lesions. The other patient developed pruritic eruptions and plaques one and a half years after gastric stapling. The diagnosis was confirmed by skin biopsy and serology. The cutaneous lesions resolved on a GFD.

In conclusion, celiac disease and related disorders should be suspected and evaluated in patients who develop suggestive symptoms after bariatric procedures. This includes procedures commonly associated with malabsorption.

\section{References}

1. Rubio-Tapia A, Ludvigsson JF, Brantner TL, Murray JA, Everhart JE (2012) The prevalence of celiac disease in the United States. Am J Gastroenterol 107: 1538-1544.

2. Tucker E, Rostami K, Prabhakaran S, Al Dulaimi D (2012) Patients with coeliac disease are increasingly overweight or obese on presentation. $J$ Gastrointestin Liver Dis 21: 11-15.

3. Sonti R, Green PH (2012) Celiac disease: Obesity in celiac disease. Nat Rev Gastroenterol Hepatol 9: 247-248.

4. de'Angelis N, Carra MC, Vincenzi F (2012) Gluten-free diet in obese patients with celiac disease: an enemy of the bariatric surgeon? Obes Surg 22: 995996.

5. Sinniah R, Roche E (2012) Letter: rising incidence of obesity in the coeliac population - amalady or maladaptation? Aliment Pharmacol Ther 35: 1483.

6. Bai J, Moran C, Martinez C, Niveloni S, Crosetti E, et al. (1991) Celiac Sprue after surgery of the upper gastrointestinal tract. Report of 10 patients with special attention to diagnosis, clinical behavior, and follow-up. J ClinGastroentero I13: 521-524.

7. Logan RF, Ferguson A (1982) Jejunal villous atrophy with morbid obesity: death after jejunoileal bypass. Gut 23: 999-1004.

8. Maple JT, Pearson RK, Murray JA, Kelly DG, Lara LF, et al. (2007) Silent celiac disease activated by pancreaticoduodenectomy. Dig Dis Sci 52: 21402144.

9. Chedid AD, Kruel CR, Chedid MF, Torresini RJ, Geyer GR (2005) Development of clinical celiac disease after pancreatoduodenectomy: a potential complication of major upper abdominal surgery. Langenbecks Arch Surg 390: 39-41.

10. Caputo M, Brizzolara R, Schiavo M,Salmaso C, Pesce G, et al. (2006) Occurrence of overt celiac disease in the elderly following total thyroidectomy. J Endocrinol Invest 29: 831-833.

11. Topal F, Akbulut S, Topcu IC, Dolek Y, Yonem O (2009) An adult case of celiac sprue triggered after an ileal resection for perforated Mecke's diverticulum. World J Gastroentero 115: 4075-4076.

12. Tyler AD, Murdoch TB, Riddell RH, Cohen Z, Silverberg MS (2011) Celiac disease detected by pouch biopsy of a patient with ileal pouch-anal anastomosis. Am J Gastroentero I106: 1367-1368.

13. Stone CD, Klein S, Mc Doniel K, Davidson NO, Prakash C, et al. (2005) Celiac disease unmasked after pancreaticoduodenectomy. JPEN J Parenter Enteral Nutr 29: 270-271.

14. Owen DA, Thorlakson TK, Walli JE (1980) Celiac disease in a patient with morbid obesity. Arch Intern Med 140: 1380-1381.

15. Thompson JS, Thompson DS, Meyer A. Surgical Aspects of Celiac Disease. American Surgeon. In press.

16. Cuenca-Abente F, Nachman F, Bai JC (2012) Diagnosis of celiac disease during pre-operative work-up for bariatric surgery. Acta Gastroenterol Latinioam 42: 321-324.

17. Kabbani TA, Goldberg A, Kelly CP, Pallav K, Tariq S, et al. (2012) Body mass index and the risk of obesity in coeliac disease treated with the gluten-free diet. Aliment Pharmacol Ther 35: 723-729. 
Citation: Tsui JM, Thompson JS, Kothari VM, Mc Bride CL. Bariatric Procedures Unmasking Celiac Disease. J Obes Bariatrics. $2014 ; 1(1)$ : 3.

ISSN: 2377-9284

18. Kovaleski CR, Jaliman D, Kumar V, Valeski JE (1997) Dermatitis herpeticformis following gastric surgery. Arch Dermatol 133: 113-114.

19. Stephan F, Haber R, Maalouf D, Tomb R. (2014) A case of dermatitis herpetiformis aftera mini-gastric bypass surgery. J Am Acad Dermatol 71: e18-e20.

20. Bolotin D, Petronic-Rosic V (2011) Dermatitis herpetiformis. Part I. Epidemiology, pathogenesis, and clinical presentation. J Am Acad Dermatol 64: 1017-1024. 